\title{
Individual Differences in Second Language Learning: the Road Ahead
}

\author{
Wen-Ta Tseng ${ }^{1} \cdot$ Xuesong (Andy) Gao ${ }^{2}$
}

Published online: 7 October 2021

(c) National Taiwan Normal University 2021

\section{Introduction}

In the past few years, several special issues on individual differences (IDs) in language learning have been published in the field of language education [6, 17], OgaBaldwin, Fryer, \& Larson-Hall [24]. These publications range from a broad scope of theme collections to a specific focus of topic modeling. For instance, the contributions to the special issue edited by de Bot and Bátyi feature a wide range of IDs constructs including age, aptitude, attitude, and motivation. On the other hand, the contributions to a more recent special issue edited by Oga-Baldwin et al. focus on language learning motivation as modeled and interpreted through a diverse lens of mainstream motivational theories such as expectancy-value theory, self-determination theory, personal investment theory, and goal theories. A much more recent special issue edited by Gurzynski-Weiss places a predominant emphasis on the investigation of the dynamic nature of individual differences in L2 learning. The empirical studies featured in these three special issues not only point to the ongoing and enduring commitment collectively embraced by IDs researchers, but also underline the challenges concerning whether IDs in language learning should be structuralized or systematized with reference to exclusively one particular theoretical framework or dual conceptually distinct yet implicitly complementary theoretical underpinnings. To elaborate, unlike IDs constructs such as anxiety, aptitude, or willingness to communicate, which receive relatively few conceptual challenges, research on both language learning motivation and language learning strategies (LLS) has undergone different stages of transitions regarding the theoretical frameworks behind the two IDs constructs [1, 29]

Wen-Ta Tseng

wenta.tseng@ntust.edu.tw

Xuesong (Andy) Gao

xuesong.gao@unsw.edu.au

1 National Taiwan University of Science \& Technology, Taipei City, Taiwan

2 University of New South Wales, Sydney, Australia 


\section{Language Learning Motivation}

The major theoretical transition in L2 motivation is featured by moving from operationalizing L2 motivation via a social-educational modeling approach to adopting a self-based viewpoint to modeling L2 motivation (e.g., [31]). The central construct underlying the social-educational model refers to integrativeness or integrative motivation, whereas the pivotal factor underlying the L2 self model refers to ideal L2 self. Despite attempts over the years to reinterpret or even replace integrativeness with ideal L2 self, as theorized by Dörnyei and his associates, it is important to note that the two conceptually distinct L2 motivational models receive equal credits from academia. Over the years, the fundamental discrepancy regarding theoretical underpinnings between the two L2 motivational models has become even clearer. As Gardner [16] critically remarks:

Cognition and affect are parallel systems. One is not superior to the other... The L2 self is a cognitive model while that of integrative motivation is an affective one... Their utility is in the validity of the models, not in their superiority over others (p. 226).

A decade later, Dörnyei [13] also explicitly recognized the theoretical divide between the two L2 motivation models:

[T] he type of identification adopted in the L2 Motivational Self System - identification with a projected future image within the person's self-concept, rather than identification with an external reference group such as the L2 community as was the case with the notion integrativeness - can serve certain purposes ( $\mathrm{p}$. $\mathrm{xx}$ ).

After nearly 30 years of numerous rounds of theoretical debates and empirical testing, readers interested in L2 motivation research can finally obtain a clear picture that integrative motivation and ideal L2 self are in actuality isomorphic and complementary. This is especially true concerning the pragmatic valences in describing and explaining learners' motivated language learning behaviors. Integrative motivation and ideal L2 self also differ in essence both in origin and by target, leading Claro (2020) to suggest that "the ideal L2 self cannot replace integrativeness" (p. 253). Dörnyei [13] also expects to see a wave of "renewed vibrancy" (p. xxi) in bringing integrative motivation back to the spotlight. As expected, one of the aims of the present Special Issue is to respond to the urgent call to action that has yet to be answered in the two prior IDs special issues.

\section{Language Learning Strategies}

The other aim of the present Special Issue is to address a similar research controversy which has remained in the field of LLS for more than 15 years. Interestingly, analogous to the debate over the concept of integrativeness and integrative motivation, 
the criticisms levelled against LLS are mainly twofold: one centers around the definition of strategies, and the other revolves around the validity of the rating scale structure underlying Oxford's [28] Strategy Inventory of Language Learning (SILL) [8, 10-12, 32]. As with the case of L2 motivation research, Dörnyei and Skehan argued that the operational definitions of learning strategies theorized by Oxford $[27,28]$ and O'Malley and Chamot $[25,26]$ tended to be "inconsistent and elusive" (p. 608). Dörnyei [12] took a bold step to equate learning strategies to "idiosyncratic self-regulated behaviour" (p. 183). Critically, Dörnyei never shows any substantial empirical evidence to prove learning strategies are idiosyncratic at all, and nor does Dörnyei ever theorize why strategies should be conceptualized as behavior rather than as technique or influences in the way he defines motivational strategies [9]. For instance, Dörnyei ([9], p. 28) defines motivational strategies in the same paragraph as "techniques that promote the individual's goal-related behaviours" and "those motivational influences that are consciously exerted to achieve some systematic and enduring positive effect [emphasis original]," respectively. Following these two definitions, it is clear that Dörnyei equated strategies to techniques and influences, but not to behavior. It is by no means clear and consistent as to why techniques can be equivalent to influences in an operational sense. Following this line of thinking, it seems fair to say that the unjustified criticisms such as "inconsistent and illusive" thrown onto learning strategies may become equally relevant and valid to motivational strategies. In this way, should motivational strategies be likewise considered idiosyncratic as in the case of learning strategies? Furthermore, Hadfield \& Dörnyei [19] created the term achievement strategies to refer to "study techniques that can be used across a range of tasks to improve learning" (p. 146), and on the same page further argued that it was imperative that learners be introduced to the "techniques that might help them to work more productively, getting them to discuss and evaluate these and finally selecting those that work best for them" (p. 146). Notably, it is clear that Dörnyei also formally associates strategies with the construct of learning achievement, which by definition is equivalent to the concept of learning strategies. When taken together, a careful review of Dörnyei's work on motivational strategies published between 2001 and 2015 seems to show that Dörnyei has been forbidding others to do what he is doing himself. Two sets of standards might have been applied to learning strategies and motivational strategies respectively, the constructs of which are, to a certain extent, interrelated.

Dörnyei $[10,11]$ further introduced the term self-regulation, a term which he argues is more capable of reflecting the concept of strategic learning. In particular, he proposed a five-factor model to indicate the possible underlying construct of self-regulatory capacity of language learning. The proposed five-factor measurement model was initially sent into empirical testing in English vocabulary learning $[32,33]$ as an attempt to complement SILL, which is in principle operationalized by behavioral items. Indeed, the call for the paradigm shift has received enormous attention from the field and raised practitioners and researchers' awareness of the divide between the quality and quantity dimensions of strategic learning. Over the years, it has been observed that the coexistence of strategy use (the quantity dimension) and proactive control of strategy use (the quality dimension) have greatly advanced readers' understanding of the underlying theoretical underpinnings of 
strategic learning. The empirical findings of gender differences have shed light on how the two complementary forms of strategic learning may become integrated to support brain study. The effect of gender differences on strategy use started to draw researchers' attention with the rise of SILL in the 1990s [14, 18, 30]. Notably, in their very large-scale empirical study $(N>1200)$, Oxford and Nyikos [30] noted that females reported more frequent strategy use than males on a latent factor called formal rule-related practice strategies. This strategic factor greatly capitalized on learners' cognitive ability to analyze and understand the linguistic codes and rules of a target language. In another study, Ehrman \& Oxford [14] further found that females also reported more frequent strategy use than males on metacognitive strategic behaviors such as checking, monitoring, and planning one's learning performance. Importantly, the findings of significant gender differences in both cognitive and metacognitive strategy use in these early primary studies provide indirect yet critical support for the later findings uncovered by functional magnetic resonance imaging (fMRI) techniques [2, 20, 22]. Overall, females showed a stronger and wider response than males not only in the amygdala, which is responsible for emotional regulation, but also in the prefrontal cortex areas, where cognitive processing and higher order mental functioning such as planning, monitoring, and problem solving occur [3]. The above discussion suggests that the quantity dimension of strategic learning as operationalized by SILL can offer diagnostic information regarding gender differences in cognitive and metacognitive functioning in the task of language learning.

On the other hand, Tseng, Liu, and Nix [34] developed and validated an instrument to tap into the quality dimension of strategy use (i.e., the proactive control of strategy use) in language learning: Self-Regulatory Control Scale for Language Learning (SRlang). Unlike what Dörnyei [10] has hypothesized, a four-factor measurement model consisting of boredom control, awareness control, goal control, and emotion control was procured. Importantly, the naming of the four factors was essentially theories-referenced, rather than intuition-guided, which allows for the inferencing of gender differences in the proactive control of strategy use in language learning. In their second phase of validity study, Tseng et al. employed latent regression modeling to further check the way in which gender difference would modulate learners' control of strategy use over the four dimensions in SRlang. Results indicated that females had significantly stronger and better proactive control of strategy use than males in boredom control, awareness control, and emotion control, but not in goal control. Essentially, because boredom control and emotion control are intrinsically associated with emotion regulation [4, 21], the neurobiological function of which the amygdala is responsible for. Sensibly, therefore, Tseng et al.'s findings can be credited with being significantly, indirectly notwithstanding, convergent with those by fMRI $[2,20,22]$, in which the responsive magnitude in emotional regulation was directly observed in the brain and more active in females than in males. Critically, the foregoing discussion further suggests that the quality dimension of strategic learning as operationalized by SRlang may provide useful information concerning gender differences in emotional regulation in the task of language learning. In sum, the recent research findings based on fMRI studies clearly suggest that both the frequency component and the control component of strategy use can be 
considered complementary regarding their theoretical value in depicting and explicating gender differences in strategic learning of a language.

\section{Introducing the Special Issue}

The orthodoxical stance of learning strategies, as well as the unique empirical significance of the two complementary forms of strategy use, has yet to be articulated and showcased in prior special issues. To address the research gap, therefore, the second aim of the present Special Issue is to inform and update readers in a timely manner of the academic merits which have been historically built-in, but have yet to receive sufficient justice from the field. In total, the current Special Issue features 7 articles which offer a balanced report and insightful update of empirical research in relation to L2 motivation and LLS research. The first section includes three articles addressing the research on L2 motivation. The first article (Kim \& Shin) examined the mediating role of integrative motivation in the causal link between self-efficacy and English achievement in a Korean sample. Through the aid of the bootstrapping technique, Kim and Shin found that the mediating effect exerted by integrative motivation was significant and meaningful. Kim and Shin's research findings suggest that learners' affective identification with the L2 community group works in synergy with learners' cognitive belief of how well they can achieve in studying a foreign language.

The second article (Cheng) in the first section investigated the effects of grit and L2 self on willingness to communicate (WTC) in a Taiwanese sample. In Cheng's study, the scale targeting grit—passion of and persistence toward a specific ultimate goal-was conceptualized by two dimensions: consistency of interest (COI) and persistence of effort (POE). The instrument measuring L2 self was operationalized by four factors: Ideal L2 self ${ }_{\text {own }}$, Ideal L2 self ${ }_{\text {other }}$, Ought-to L2 self ${ }_{\text {own }}$, Ought-to L2 self $f_{\text {other }}$. By using hierarchical regression modeling, Cheng found that three types of L2 self-images (ideal L2 self $_{\text {own }}$, ideal L2 self ${ }_{\text {other }}$, and Ought-to L2 self ${ }_{\text {own }}$ ), taken together with grit, could jointly exert explanatory power over WTC. Cheng suggests that both establishing a gritty attitude and shaping an ideal L2 self vision carry equal weight in sustaining L2 motivation.

In the third article of the first section, Soltanian and Ghapanchi approached L2 motivation from the viewpoint of "investment," a concept that views L2 learning as an entity of social practice. Soltanian and Ghapanchi's study explored the factors that might affect Iranian EFL learners' investment through a qualitative inquiry. The results of their study revealed that the economic, social, cultural, and symbolic capital jointly influenced varying degrees of Iranian EFL learners' willingness to learn English. The reason for including a paper which focused on investment is that both investment theory [7, 23] and Gardner's [15] socio-education model underlined language learners' connections to the social world they live in.

The second section of the present Special Issue contains the other three articles with a focus on strategic learning. The first article (Nathan et al.) was featured by constructing a systematic review of the core components of LLS research conducted in Taiwan. Upon an extensive, thorough search of literature via numerous 
databases, Nathan et al. successfully extracted 100 empirical studies eligible for systematic review. The 100 primary studies were analyzed based on three evaluation criteria: (a) contexts and participant characteristics; (b) theoretical-conceptual aspects; and (c) methodological characteristics. The researchers observed that, as a whole, there was a pendulum shift from a predominant adoption of survey tools to a more diversified deployment of multiple research approaches and recognized the shift as positive. Nathan et al. suggest that situating LLS in a social-politically unique context (i.e., Taiwan) helps move the research on LLS ahead in an even more global context.

In the second article of the second section, Haga and Reinders investigated the emotional regulation of feedback on language learning in a sample of diverse L1 backgrounds including Bulgarian, Hungarian, Mexican, Polish, and Russian. Haga and Reinders applied dynamic systems theory (DST) to record and systematize a large set of interview data collected from 25 participants. Their findings showed that although participants experienced a wide range of positive and negative emotions, negative emotions could have facilitative effects on language learning, particularly on shaping learners' multilingual identities. Haga and Reinders suggested that future research needs to be oriented to a deeper understanding of emotions and emotional regulation in language learning.

The third study (Koenig \& Guertler) included in the second section conducted a two-phase large-scale consecutive survey study to explore German learners' thoughts and perceptions of improvement and satisfaction regarding their selfregulated language learning. Sample 1 and sample 2 involved 1646 and 796 participants situated in the German higher educational context. The results of the phase I survey study showed that time investment in self-regulated study could lead to greater language skill improvement. The results of the phase II retrospective survey study further indicated that German college learners had not yet cultivated enough required capacity to self-regulate their language learning strategies. The findings of Koenig and Guertler's study pointed to the individuality and variations observed at the nexus where the quality dimension (self-regulatory capacity) and the quantity dimension (use of language learning strategies) of strategic learning intersected.

The present Special Issue concludes with an updated critical review of the role of individual differences in language learning and teaching from a complex-dynamic and socio-ecological perspective. This wide lens allows readers to holistically visualize the road ahead of IDs research in language learning. Griffiths featured 11 salient IDs factors considered to be important in L2 classrooms. Based on the results of an empirical investigation with L2 teachers, Griffiths pointed out that motivation and strategy use were ranked as the most important factors and the other factors such as aptitude and gender as at least somewhat important. The findings led Griffiths to suggest that there is a need for future research to take a holistic approach to advance the understanding of the potential interplay among the 11 salient IDs factors in language learning. 


\section{Conclusion}

To conclude, we believe the 7 articles collected in this Special Issue have made unique yet valuable contributions to the field of IDs research in language learning. Upon the publication of the Special Issue, we hope that researchers and practitioners alike can be enlightened in a timely manner by the theoretical clarifications critically needed in the field. Readers should look forward to not only renewed, but also heightened vibrancy regarding innovative applications and integrations of different IDs factors deemed to be significant and critical in the field of language learning.

\section{References}

1. Al-Hoorie, A. H., \& MacIntyre, P. D. (Eds.). (2020). Contemporary language motivation theory: 60 years since Gardner and Lambert (1959). Multilingual Matters.

2. AlRyalat, S. A. (2017). Gender similarities and differences in brain activation strategies: Voxelbased meta-analysis on fMRI studies. Journal of Integrative Neuroscience, 16, 227-240.

3. Baars, B., \& Gage, N. M. (2010). Cognition, brain, and consciousness: Introduction to cognitive neuroscience (2nd ed.). Elsevier Ltd.

4. Boekaerts, M. (2011). Emotions, emotion regulation, and self-regulation of learning. In B. J. Zimmerman \& D. J. Schunk (Eds.), Handbook of self-regulation of learning and performance (pp. 408-425). Routledge.

5. Claro, J. (2019). Identification with External and Internal Referents: Integrativeness and the Ideal L2 Self. In A. Al-Hoorie \& P. MacIntyre (Eds.), Contemporary Language Motivation Theory (pp. 233-261). Multilingual Matters.

6. de Bot, K., \& Bátyi, S. (Eds.). (2017). Individual differences in second language development [Special issue]. Studies in Second Language Learning and Teaching, 7(1).

7. Darvin, R., \& Norton, B. (2015). Identity and a model of investment in applied linguistics. Annual Review of Applied Linguistics, 35, 36-56.

8. Dörnyei, Z., \& Skehan, P. (2003). Individual differences in second language learning. In C. J. Doughty \& M. H. Long (Eds.), The handbook of second language acquisition (pp. 589-630). Blackwell.

9. Dörnyei, Z. (2001). Motivational strategies in the language classroom. Cambridge University Press.

10. Dörnyei, Z. (2005). The psychology of the language learner: Individual differences in second language acquisition. Lawrence Erlbaum.

11. Dörnyei, Z. (2006). Individual differences in second language acquisition. AILA Review, 19, 42-68.

12. Dörnyei, Z. (2009). The psychology of second language acquisition. Oxford University Press.

13. Dörnyei, Z. (2020). Foreward. In A. Al-Hoorie \& P. MacIntyre (Eds.), Contemporary language motivation theory (pp. xix-xxi). Multilingual Matters.

14. Ehrman, M., \& Oxford, R. (1989). Effects of sex differences, career choice, and psychological type on adult language learning strategies. The Modern Language Journal, 73, 1-13.

15. Gardner, R. C. (1985). Social psychology and second language learning: The role of attitudes and motivation. Edward Arnold.

16. Gardner, R. C. (2010). Motivation and second language acquisition. Peter Lang Publishing Inc.

17. Gurzynski-Weiss, L. (2020). Investigating the dynamic nature of learner individual differences in L2 learning. [Special issue]. Studies in Second Language Learning and Teaching, 10 (1).

18. Green, J. M., \& Oxford, R. (1995). A closer look at learning strategies, L2 proficiency, and gender. TESOL Quarterly, 29, 261-297.

19. Hadfield, J., \& Dörnyei, Z. (2013). Motivating learning. Longman.

20. Koch, K., Pauly, K., Kellermann, T., Seiferth, N. Y., Reske, M., Backes, V., \& Habel, U. (2007). Gender differences in the cognitive control of emotion: An fMRI study. Neuropsychologia, 45, 2744-2754. 
21. Macklem, G. L. (2015). Boredom in the classroom: Addressing student motivation, self-regulation and engagement in learning. Springer.

22. McRae, K., Ochsner, K. N., Mauss, I. B., Gabrieli, J. D., \& Gross, J. J. (2008). Gender differences in emotion regulation: An fMRI study of cognitive reappraisal. Group Processes \& Intergroup Relations, 11, 143-162.

23. Norton, B. (2013). Identity and language learning: Extending the conversation. Bristol: Multilingual matters.

24. Oga-Baldwin, W. L. Q., Fryer, L. K., \& Larson-Hall, J. (2019). The critical role of the individual in language education: New directions from the learning sciences [Special issue]. System, 86.

25. O’Malley, J. M., \& Chamot, A. U. (1990). Learning strategies in second language acquisition. Cambridge University Press.

26. O’Malley, J. M., \& Chamot, A. U. (1994). Learning strategies in second language learning. The International Encyclopedia of Education (Vol. 6, pp. 3329-3335). Pergamon Press.

27. Oxford, R. L. (1989). Use of language learning strategies: A synthesis of studies with implications for strategy training. System, 17, 235-247.

28. Oxford, R. L. (1990). Language learning strategies: What every teacher should know. Heinle and Heinle.

29. Oxford, R. L. (2017). Teaching and researching language learning strategies: Self-regulation in context (2nd ed.). Taylor \& Francis.

30. Oxford, R., \& Nyikos, M. (1989). Variables affecting choice of language learning strategies by university students. The Modern Language Journal, 73, 291-300.

31. Schmidtke-Bode, K., \& Kachel, G. (2020). Exploring the motivational antecedents of Nepalese learners of L2 English. International Review of Applied Linguistics in Language Teaching, 58(4), 379-418.

32. Tseng, W.-T., Dörnyei, Z., \& Schmitt, N. (2006). A new approach to assessing strategic learning: The case of self-regulation in vocabulary acquisition. Applied Linguistics, 27, 78-102.

33. Tseng, W. T., \& Schmitt, N. (2008). Toward a model of motivated vocabulary learning: A structural equation modeling approach. Language Learning, 58, 357-400.

34. Tseng, W. T., Liu, H., \& Nix, J. M. L. (2017). Self-regulation in language learning: Scale validation and gender effects. Perceptual and Motor Skills, 124, 531-548.

Publisher's note Springer Nature remains neutral with regard to jurisdictional claims in published maps and institutional affiliations. 